\title{
RAZVOJ RAČUNARSKE IGRE ČIJI JE CILJ SPASENJE TRADICIONALNOG ANTAGONISTE
}

\section{DEVELOPMENT OF A COMPUTER GAME AIMED AT ASVING THE TRADITIONAL ANTAGONIST}

\author{
Božidar Kljajević, Fakultet tehničkih nauka, Novi Sad
}

\begin{abstract}
Oblast - ELEKTROTEHNIKA I RAČUNARSTVO
Kratak sadržaj - Zadatak projekta bio je razviti računarsku igru od samog početka, odnosno osmišljanja ideje pa sve do krajnje realizacije računarske igre. Za realizaciju projekta krišćeni su Uniti (Unity), Blender (Blender) $i$ Photoshop (Photoshop). Za potrebe igre osmišljene su pozadinska priča i priča igre, koje prate dašavanja u igri. Ciljevi igre su pomoći smrti, tradicionalnom antagonisti, i preživeti u ostatku igre. Kao rezultat dobijena je potpuno realizovana avantura kao zanimljiva računarska igra.
\end{abstract}

Ključne reči: Razvoj video igre, dizajn, modelovanje, priča, nivoi

\begin{abstract}
The task of the project was to develop a computer game from the very beginning, ie from the conception of the idea until the final realization of the computer game. Unity, Blender and Photoshop were named for the realization of the project. The background story and the story of the game are designed for the needs of the game, which follow the events in the game. The goals of the game are to help death, traditional antagonists, and survive in the rest of the game. The result is a fully realized adventure as an interesting computer game.
\end{abstract}

Keywords: Video game development, design, modeling, story, levels

\section{UVOD}

Projekat koji se realizuje predstavlja video igru, čiji se razvoj prati od samog početka, od predstavljanja ideje, preko priče, razvoja i problema svih pratećih delova igre, do konačne verzije. Ideja je potekla od želje da se spoji više elemenata različitih žanrova objedinjenih u avanturu. Naziv projekta odnosno igre je From Beyond, što znači Sa one strane. Za realizaciju igre korišćeni su Unity, Blender i Photoshop.

Smrt je zarobljena. Da li si spreman da kreneš u avanturu? Vođen legendarnom pričom ulaziš u mračne prostorije sa ciljem da pronađeš smrt i da je oslobodiš kako bi stvari ponovo normalno funkcionisale. Kako se suočiti sa smrću i kako je osloboditi? Istražuj, suoči se sa strahovima i pobedi.

\section{NAPOMENA:}

Ovaj rad proistekao je iz master rada čiji mentor je bio dr Dragan Ivetić, red. prof.
From Beyond je žanrovski određena kao avantura, ali u sebi krije i elemente drugih žanrova. Avantura uključuje istraživanje, rešavanje zagonetki, prikupljanje, dekodiranje poruka i kretanje lavirintima. Igra je third person realizovana u 3D-u i prvenstveno razvijana za PC. Igra prati Iroasa, glavnog junaka, koji je spletom okolnosti izabran da krene u avanturu u mračni svet sa ciljem da oslobodi Thanatosa, odnosno smrt, kako bi svet ponovo normlano funkcionisao. Cilj u igri je istražiti, rešiti i sakupiti potrebno. Glavni cilj je osloboditi zarobljenu smrt. Smrt se osloađa kada se pronađe lobanja i donese do smrti. Ono što igru čini jedinstvenom je svakako zabavan gameplay, ali i kako je već napomenuto jedinstvena kombinacija više elemenata drugih žanrova u okviru avanture. Kombinacija horora i mozgalica uklopljenih u jednu igru. Originalna pozadinska priča (eng. backstory) data je u igri i nadograđena fantastičnom pričom same igre. Priča ima zanimljiva dešavanja i fantastično prati sva dešavanja u igri. Ono što predstavlja jedinstvenost igre je činjenica da je u igri potrebno osloboditi smrt. Dok je u igrama standardno pravilo boriti se protiv smrti ili je smrt predstavljena kao nešto nepoželjno, u igri From Beyond cilj je pomoći smrti i osloboditi je.

From beyond je namenjen ljudima širom sveta, bez geografskih ograničenja ili tendencija na nekom delu sveta. Sa druge strane, što se tiče starosne granice, igra je namenjena tinejdžerima starijim od 12 godina i odraslim osobama. Namenjena je avanturistima, osobama koje vole horor, misteriju, fantastiku, zagonetke i istraživanje. Cilj je da se kod igrača izazove osećaj uzbuđenja, ali i straha, čemu doprinose ambijent i muzika u igri. Takođe kod korisnika se izaziva ushićenje, odnosno želja za napredovanjem. Kad otkrije ili reši neki deo, kod korisnika se formira uzbuđenje i želja da vidi šta je sledeće, te nastavlja da igra. Od igrača se očekuje i razmišljanje i rešavanje zagodnetki koje nisu jednostavne, a to je još jedan od razloga zašto je granica za igrača postavljena na minimum 12 godina. Estetika je prisutna $u$ igri i ima za cilj da izazove estetsku zahvalnost igrača, ali pored estetskog momenta neki predmeti koji doprinose estetici kriju i značajne informacije u igri.

\section{NARATIVNI DIZAJN}

Ono što treba da pokrije jedan dobro odrađen narativni deo igre nije samo glavna priča koja prati igru, već i dešavanja pre ili eventualno posle glavne radnje. Radnja, odnosno priča koja nosi glavni teret svakako jeste onaj deo koji je prisutan u radnji igre, ali podjednako je bitno 
dati i uvid u stvari kako se došlo do radnje u igri, odnosno predstaviti širu sliku ili dati pozadinsku priču koja objašnjava glavna dešavanja, tačnije glavne probleme u samoj radnji igre.

\subsection{Pozadinska priča}

Pre mnogo godina, vođeni idejom o životu bez smrti, četiri učena čoveka tog vremena, među kojima je bio jedan slikar, okupili su se u mračnim i zabačenim prostorijama sa idejom da smisle plan kako da zarobe smrt. Smrtnost je deo čovekove priode, ali oni su hteli to da promene $\mathrm{i}$ da ljudi postanu besmrtni. Izvodili su eksperimente opasne po zivot, kako bi namamili smrt da dodje ka njima. Smrt je došla i upala u već pripemljenu i osmišljenu zamku. Oduzeli su joj lobanju kako ne bi mogla da izađe i na taj način smrt ostaje zarobljena. Slikar uviđa da prave grešku, ali njegovi saradnici ne žele da ga slušaju. Smrt ostaje zarobljena i od tog momenta ljudi žive večno, bez umiranja. Prirodni proces umiranja je narušen, ljudi žive sa opakim bolestima koje bi se $u$ prirodi stvari završavale smrću, ali sada smrti nema i ljudi žive sa bolestima i muče se.

\subsection{Priča igre}

Priča počinje sa prikazom problema u stvarnom svetu junaka. Ljudi dugo žive, nema umiranja, moge bolesti ne završavaju se smrću, već ljudi žive sa tim opakim bolestima i muče se. Nije to život, ali smrti nema, prirodni proces je narušen već duže vreme. Iroas saznaje za legendu o smrti, odnosno kako je smrti oduzeta lobanja i kako je zarobljena. Zaintrigiran je legendom, ali nema dovoljno hrabrosti da se upusti u avanturu. Ne želi da napusti porodicu i bliske ljude, jer neki od njih su bolesni. Takođe u Iroasovoj glavi se ponavlja pitanje "Da li je smrt na našoj strani, da li je pametno osloboditi je?". Čarobnjak Magos daje Iroasu datalje o legendi i otkriva mu destinaciju gde mora poći u nameri da oslobodi smrt. Iroas prihvata izazov i odlazi na mračno mesto gde smrt čeka zarobljena. Iroas mora rešiti testove i zagonetke kako bi prešao prepreke koje su stavljene ispred njega. Susreće se sa Thanatosom - smrt i shvata da nema povratka nazad. Thanatos daje Iroasu zadatak da pronađe lobanju i da mu je donese. Na tom putu ga čeka još testova, koje ako ne reši i ne donese lobanju, ostaje zarobljen sa Thanatosom u mračnim prostorijama. U skrivenoj prostoriji konačno pronalazi lobanju koju traži. Thanatos dobija lobanju i konačno je slobodan. Pokazuje Iroasu put, ali taj put nije bezbedan. Kako bi pobegao sa ovog mračnog mesta pred Iroasom su nova iskušenja i ne sme praviti greške sada kada je smrt slobodna i motri na njega. Kako je Iroas oslobodio Thanatosa, prirodni proces umiranja je ponovo uspostavljen.

\section{KARAKTERI}

U svakoj video igri bitan deo priče i igre su karakteri. Igrači se često poistovete sa glavnim karakterom ili im pažnju privlači neki od sporednih karaktera. Kao glavni nosioci radnje karakteri moraju biti autentični i adekvatno usklađeni sa pričom i ambijentom radnje. Na sceni u video igri prisutna su tri karaktera, dok se u priči pominju još neki. U igri su prisutni glavni lik Iroas, Thanatos karkater koji predstavlja smrt i Magos - čarobnjak, odnosno mentor i pomoćnik u igri.

\subsection{Modelovanje i animiranje}

Prvi korak u realizaciji je samo modelovanje karaktera. Kako se modeluje karakter čija je namena da se koristi u video igri, onda se model pravi tako da bude Low Poly model. Glavna ideja je da model bude sačinjen od manjeg broja poligona kako bi model zahtevao manje računarske snage za renderovanje. Stoga se Low Poly modeli i koriste $\mathrm{u}$ video igrama i sistemima virtuelne realnosti.

Ovako napravljen model se dalje priprema za dodavanje teksture. Model se odmota (eng. unwrap), odnosno ceo model se prikaze na $2 \mathrm{~d}$ površini kako bi se na njega primenila odgovarajuća tekstura. Da bi se model odmotao, na modelu su ručno pravljeni rezovi (eng. seams) kako bi model mogao da se prikaže u $2 \mathrm{~d}-\mathrm{u}$. Rezovi su pravljeni tako da se uglavnom nalaze na ivicama modela, kada je to bilo moguće, ili na delovima tako da rezovi budu što manje uprečatljivi i vidljivi. Nakon određenih rezova model se transformiše u UV mapu, odnosno $2 \mathrm{~d}$ delove modela prikazane u ravni. Na tako razvijen model u $2 \mathrm{~d}$ potrebno je primeniti teksturu. Kako bi se primenila tekstura kao jedna slika, ručno je pravljena takva slika, delom u Blenderu, delom u Photoshopu. Nakon primene teksture na model, sledeći korak $u$ realizaciji funkcionalnog modela je rigovanje, odnosno ubacivanje skeleta. Za pravljenej skeleta iskorišćena je opcija koju nudi Blender, a to je Basic Human Meta-Rig. Primenom ove opcije dobija se skelet, nakon čega se kosti pažljivo i precizno postave na odgovarajuće pozicije tako da se poklapaju sa prethodno kreiranim karakterom. Nakon preciznog postavljanaj kostiju na odgovarajuće pozicije, koristi se Generate rig, postojeća opcija u Blenderu koja omogućava povezivanje kostiju i kontrolu na ispravan način. Nakon što je skelet napravljen potrebno je povezati karaktera i kosti u procesu koji se zove skinning. Model je parent-ovan na kosti sa automatic weighs, a zatim $\mathrm{u}$ weight paint modu su dorađene težine gde je bilo potrebno. Na ovaj način svaka tačka modela povezana je određenim procentom za odgovarajuće kosti. Ovako odrađen model spreman je dalje za animiranje. Odrađene su tri animacije: idle, hod i skok. Idle je jednostavna animacija sa animiranjem tri kontrole tako da se stekne utisak da karakter diše. Animacija traje 34 frejma i prvi i poslednji frejm su isti kako bi se mogao efikasno uključiti loop animacije. Animacija hoda je takođe loop animacija gde prvi i poslednji frejm izgledaju isto, s tim da u sredini postoji frejm koji je suprotan od početnog i krajnjeg, odnosno suprotne ruke i noge se nalaze napred i nazad. Urađene su ključne poze: contact, down, pass, up. Treća animacija je animacija skoka koja se sastoji iz tri animacije, kako bi posle mogle odvojeno biti implementirane u igri. Prva animacija je odskok, koja prelazi u animaciju inAir, odnosno animaciju padanja, koja ide u loop sve dok karakter ne treba da se dočeka, a tada ide treći deo, odnosno doskok.

\subsection{Sinopis likova}

Poznati psiholog Karl Jung objašnjava razlog za pripovedanje u smislu nesvesnog znanja sa kojim smo svi rođeni, a opet možemo da ga nikada ne budemo direktno svesni. U okviru ovog znanja nalaze se univerzalne teme i arhitipovi koji se pojavljuju u obliku priča i tipova likova u umetnosti, muzici, književnosti, filmu i igrama. 
Arhetipovi se koriste u svim zabavnim medijima kako bi pojačali vezu publike sa pričom. Arhetipovi po Jungu prisutni u igri From Beyond: heroj, mentor, čubar i senka.

Heroj - suočava se sa problemom priče, sprovodi radnju igre, preuzima rizik i odgovornost. Sinopis lika - Ime:

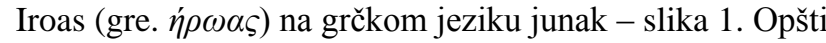
tip: fantastični, stvoren samo za potrebe igre. Karakter je muškog pola, starosti između 25 i 30 godina. Fizički izgled: karakter prosečne građe, izgledom predstavljen kao prosečan čovek iz naroda, akcenat je na njegovoj moralnoj veličini. Vizuelne karakteristike - četiri boje (crvena, crna, zelena i siva). Na jakni oslikan zmaj (hrabrost, odvaţnost). Na glavi šlem kao unikatan deo karaktera - sigurnost. Razvoj lika - Ide na putovanje da reši problem koji je zadesio ne samo njega, već i celokupno čovečanstvo. Moralnu snagu pokazuje kada problem svih ljudi stavlja u prvi plan, gde pokazuje brigu ne samo za sebe već i za zajednicu. Razvoj lika se ogleda u njegovoj bojazni da krene na put, hrabrosti da ipak ode $\mathrm{u}$ avanturu i suoči se sa izazovima, preko susreta sa smrću, i konačnog povratka gde je junak sad bogatiji za jedno veliko iskustvo. Pokazuje da može da se nosi sa strahom i legendom o smrti. Pokret - ciklus kretanja i idle prikazuju da je heroj hrabar i siguran u sebe, iako se nalazi na opasnom mestu i na opasnoj misiji, ipak pravi brze i odvažne pokrete i užurbano se kreće ka opasnosti.

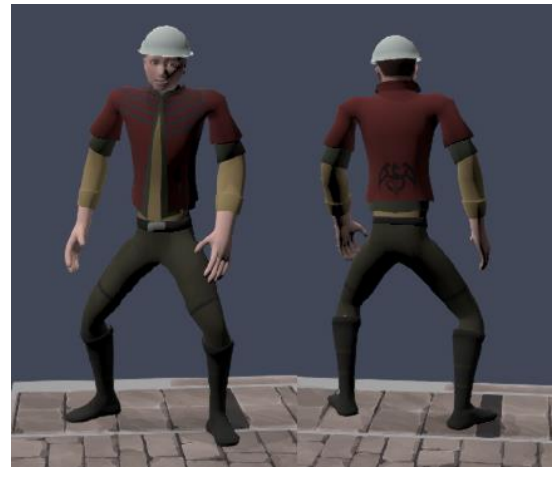

Slika 1. - Iroas - glavni junak

Mentor - stariji savetnički lik, oslonac heroja u avanturi. Ime: Magos (gre. mágos), što na grčkom jeziku znači čarobnjak. Opšti tip: mitski, u mitskim pričama često se pominju čarobnjaci. Lik je muškog pola, starosti oko 400 godina. Fizički izgled: visine iste kao heroj, seda i duga kosa, seda brada. Vizuelne karakteristike - dominira siva boja, sivo odelo, plašt, šešir i štap. Osobine - čarobnjak je mudar, živi dovoljno dugo da poznaje događaje koji čekaju heroja. Simboli mudrosti kao kod svakog čarobnjaka su dugačka brada, šešir i štap. Čarobnjak poznaje legendu o smrti, daje dovoljno informacija samom heroju. Vokalne karakteristike: dubok i smiren glas.

Čuvar - heroju blokira napredovanje junaka dok junak ne dokaţe svoju vrednost, u ovom slučaju dok ne donese potreban predmet. Sinopis lika: Ime: Thanatos (gre. $\theta \dot{\alpha} v \alpha \tau o \varsigma)$, na grčkom jeziku znači smrt. Opšti tip: mitski, smrt se često pominje u mitovima i legendama. Lik je muškog pola, besmrtan. Fizički izgled: lik smrti je viši malo u odnosu na heroja, krupniji je od heroja. Vizuelne karakteristike - dominira crna boja, crni plašt. Na rukama ima duže nokte nalik na kandže. Iskrzali i pocepani krajevi odeće. Osobine - nestrpljiva, željna slobode, takože mudra. Pokret - Idle animacija oslikava neki vid tapkanja u mestu, odnosno bespomoćnost i nestrpljenje smrti. Smrt se takođe nestrpljivo kreće u krug po prostoriji, dok se ne susretne sa Iroasom, kada prelazi u Idle.

Senka - četiri vidjenija čoveka tog vremena. Razmišljaju suptorno od heroja. Odgovorni su za problem koji je zadesio heroja. Nisu u potpunosti zli, već imaju suprotan stav od heroja po pitanju smrti. Pohlepno su postupili bez razmišljanja o posledicama i tako naneli zlo svima.

\section{GAMEPLAY}

$\mathrm{Na}$ početku igre Iroas je u prostoriji iz koje vode samo jedna vrata. Vrata su zaključana i mogu se otvoriti samo unošenjem tačne lozinke. U istoj prostoriji nalazi se slika koja trenunto Iroasu ne može pomoći i namenjena je za nastavak igre. $\mathrm{Na}$ jednom od zidova nalazi se kvadrat koji se rotira i koji krije šifru od vrata. Nedostajuća mesta na kvadratu koja su obeležena zvezdicom predstavljaju šifru za vrata. U pitanju je niz brojeva od 85 do 92 . Ovaj niz je odabran jer cifre koje nisu pod zvezdicom su 0, 6, 8 i 9, a kako se kvadrat rotira ove cifre imaju smisla i rotirane. Kada Iroas priđe šifratoru od vrata i Igrač pritisne komandu E otvara se šifrator i moguće je uneti šifru. Nakon otključavanja i prolaska kroz vrata Iroas zatiče Thanatosa u kružnom užurbanom hodu. Kada Iroas priđe Thanatosu on se zaustavi - slika 2. Pri susretu sa Thanatosom, glavni izazov Iroasu daje baš on. Thanatos daje Iroasu zadatak da pronađe lobanju koja je sakrivena. $\mathrm{Ne}$ daje mu previše informacija, ali obećava pomoć u nastavku ako mu donese lobanju.

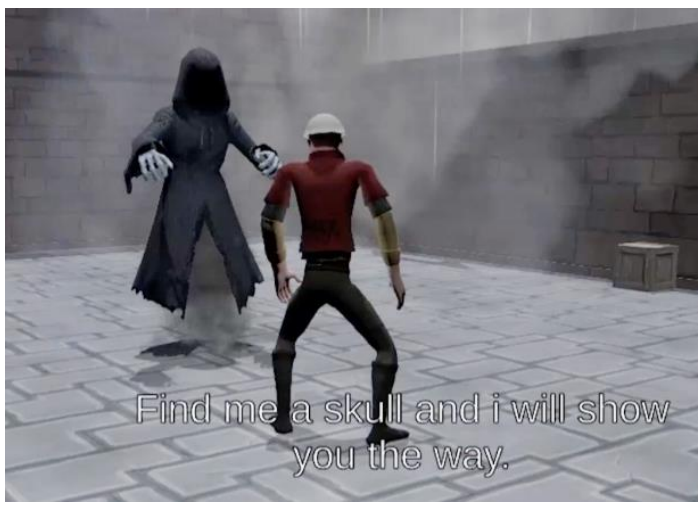

Slika 2. - Susret sa Thanatosom

Sada se pred Iroasom nalazi dvoje vrata. Jedna vrata zahtevaju ključ kako bi se otvorila a druga unos tačne šifre. Kako trenutno ključ nije moguće naći, igrač se usresređuje na vrata koja zatevaju lozinku. Iznad šifratora se nalazi kruna sa četiri kruga na vrhu, a pored umetničkih dela na zidovima takođe se nalaze krune ali sa po jednim krugom koji označava redosled lozinke. Ovo označava da se na slikama krije lozinka za otvaranje ovih vrata. I dalje je primarni cilj pronaći lobanju. Otključavanjem vrata čiju su šifru krile slike, Iroas ulazi u novu prostoriju u kojoj se ne nalazi lobanja, ali koja naizgled nema izlaz i ne vodi nigde. Još jednom umetničke slike na zidovima imaju ključnu ulogu u otkrivanju tajne prostorije. Četiri protreta, gde svaki pokazuje prstom u smeru gde igrač treba da se kreće i gde je skrivena prostorija. Pored svake slike nalazi se simbol ruke sa uperenim kažiprstom, što predstavlja pomoć 
igraču da obrati pažnju na šta portreti sa slike pokazuju. Kada igrač isprati putokaze koji pokazuju slike nailazi na zid koji izgleda kao ćorsokak, ali kada se igrač dovoljno približi zidu vidi se prolaz na zidu, kroz koji igrač može da prođe. Iza prolaza je skrivena prostorija gde se nalazi lobanja koju Iroas traži. Kada se pokupi lobanja pritiskom komande E, potrebno je istim putem vratiti se do Thanatosa i doneti mu lobanju. Thanatos kao što je i obećao otvara novi put za Iroasa. Novi put čine plaforme kojima se Iroas mora kretati kako bi uspeo da pobegne sa ovog mračnog mesta. Put započinje sa nekoliko platformi u vidu stepenika, zatim prelazak preko uske grede. Nakon grede Iroas mora da skoči na platfomu koja se kreće napred nazad nakon koje sledi još jedna uska greda. Sledeći izazov za Iroasa predstavljaju platforme koje padaju čim stane na njim, tako da se preko njih mora brzo kretati i na njima se ne zadržava.

Naredna platforma se kreće na gore kada Iroas stane na nju i vodi ga direktno do portala kroz koji Iroas mora proći. Nakon prolaska kroz portal Iroas se nalazi u središtu olujnih oblaka i od pada i gubitka života ga dele samo platforme. Iroas u trenutku prolaska kroz portal ima dva života i sada kada je smrt slobodna mora pažljivo da se kreće. Nakon prolaska kroz portal Iroas se susreće sa Magosom koji za igrača predstavlja sigurnu tačku, odnosno ako padne sa platformi biće vraćen na ovu poziciju ako mu je preostalo života. Pred Iroasom je naredna prepreka u vidu platformi gde neke platforme padaju, a neke ne, tako da nije siguran na kojoj platformi se sme zadržati, a na kojoj ne sme, stoga se mora brzo kretati. Nakon prelaska platformi koje padaju pred Iroasom se nalazi lavirint. Glavna karakteristika Lavirinta je da se sastoji od platformi i da se u odnosu na platformu na kojoj se stoji uvek pojavljuju jedna platforma napred $\mathrm{i}$ jedna nazad. Ovako pojavljivanje platformi usporava igrača da se polako i pažljivo kreće i unapred razmišlja gde bi trebalo da ide. Prva raskrsnica u lavirintu daje Iroasu mogućnost levog i desnog puta. Ako izabere levi put i nastavi njime da se kreće, ponovo će doći na raskršće, gde jedan put vodi ka prikupljanju dodatnog života, a drugi put vodi ka prikupljanju ključa. Nakon što prikupi neophodan ključ i ako je potrebno dodatni život, Iroas se vraća na početno raskršće i kreće na desnu stranu. Nakon kretanja ovim putem ponovo nailazi na raskršće, ovoga puta jedan put je pogrešan i vodi u ćorsokak, a drugi put vodi ka novom portalu. Nakon prolaska kroz ovaj portal Iroas biva vraćen na prethodno područje ispred vrata za koja je bio potreban ključ. Ukoliko igrač ne sakupi ključ mora istim putem da ide ponovo do lavirinta gde se ključ nalazi. Ako je ključ ipak pokupljen kada se priđe vratima koja zahtevaju ključ, ona će se otvoriti i Iroas će moći da napusti ovo mračno mesto. Prolaskom kroz poslednja vrata Iroas je uspešno rešio zadatke, vratio je lobanju smrti i na taj način smrt je slobodna, a zatim je sebe spasao i pobegao je sa tog strašnog mesta.

\section{ZAKLJUČAK}

Igra From Beyond uspešno je realizovana. Cilj je bio napraviti igru žanrovski određenu kao avantura, ali sa elementima i drugih žanrova. Uklapanjem elemenata drugih žanrova sa avanturom dobija se širi spektar potrncijalnih korisnika, odnosno igrača. Rezultat predstavlja kompletno formirana igra realizovana u četiri scene. Prva scena koja je realizovana da bude početna gde igrač može da oseti atmosferu koja ga očekuje u nastavku i odmah u prvoj sceni se upoznaje sa glavnim junacima igre. Druga scena je namenjana da se sazna šta su problemi u igri i kako su ti problemi nastali, odnosno pozadinska priča o nastanku sveta igre. Treća scena predstvalja srž igre, odnosno na njoj su smeštena sva dešavanja u igri. Ova scena krije sve zadatke i avanture namenjene korisnicima. Poslednja scena aktivira se po uspešnom rešavanju svih prepreka i zadataka i predstavlja potvrdu igraču da je uspešno prešao igru.

Glavnu autentičnost igre predstavlja jedan od ciljeva igre, tačnije u igri je određen zadatak da se oslobodi smrt. Smrt je $u$ većini igara i priča prestavljena u liku antagoniste, ali u igri From Beyond cilj je pomoći smrti. Kao rezultat ovog nesvakidašnjeg cilja, igra postaje jedinstvena $i$ drugačija.

Dobro usaglašen narativni dizajn i realizacija priče pretvorena u video igru bili su ključ za uspeh. Igra je razvijana prvenstveno za $\mathrm{PC}$, ali postoji mogućnost njenog lakog prenosa i na ostale platforme. Adekvatna priča i realizacija mogu da posluže kao inspriacija za pravljenje stvarnog escape room-a sa zadacima i zagonetka realizovanim okviru stvarnog prostora. Danas je sve prisutnije da se na osnovu video igre prave filmovi i serije. Igra From Beyond sa svojom autentičnom pričom ima veliki potencijal da se u budućnosti na osnovu nje uradi film ili serija. Pored svih navedenih potencijala, najbitniji potencijal igre ogleda se $u$ mogućnosti formiranja nastavka igre. Priča i igra su dovoljno intrignatne i otvorene, tako da postoji prostor formiranja nastavka kako priče tako i igre. Nastavak i budući projekat mogli bi da obuhvate dešavanja koja su nastala nakon oslobađanja Thanatosa. Mogući sled dodađaja mogao bi da uključi i ponovno udruživanje Iroasa i Thanatosa, ali ovaga puta Iroas bi bio negativac obavljao bi prljav posao za Thanatosa. Nakon oslobađanja Thanatos je oduzeo život Iroasovoj voljenoj osobi, ali mu je obećao da će je vratiti ako se povinuje njegovim naredbama. Thanatos drži Iroasa u šaci i pravi od njega negativca. Priča bi pratila glavnog karaktera koji ne bi spasavao svet i radio u službi dobra, već bi igra pratila Iroasa koji je zaslepljen obećanjima Thanatosa postao negativca. Realizacija ove potencijalne ideje i igre, kao nastavka igre From Beyond, gde igra prati nekada pozitivnog lik, a sada negativca koji ima tendenciju da ponovo bude na strain dobra, predstavlja veliki potencijal. Ova ideja za nastavak igre otvara vrata budućim projektima i uspešnim nastavcima igre From Beyond.

\section{Kratka biografija:}

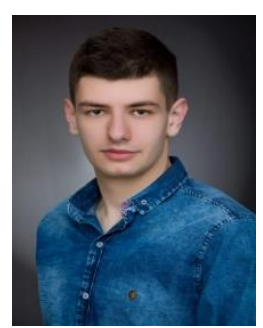

Božidar Kljajević rođen je u Novom Sadu 1997. god. Fakultet tehničkih nauka upisao je 2016 god. Na studijskom programu Računarstvo i Automatika. Bečelor rad odbranio je 2020. god. Master rad na usmerenju Multimedija i računarske igre odbranio je 2021. god. kontakt: bozidar.kljajevic07@gmail.com 